\title{
Lessons Jesuit Business Programs Can Learn from Chinese MBA Programs
}

\author{
Mary Ann McGrath ${ }^{1}$
}

\begin{abstract}
North American Schools of Business have been "going global" by transplanting pedagogy and content to Asia and Africa for several centuries. From a teaching perspective, our western schools look to these regions as contexts to provide richness to our students' educational experience, to prepare Americans for dealings in the global business marketplace, and often to increase our own enrollments and revenues. To date we have served as "exporters" of our own Western brand of MBA education.

Using an ethnographic approach of participant observation gained through two years of teaching and living in China supplemented with interviews with Chinese students studying in the U.S., this paper suggests an alternative view. China in particular and Asia in general present a different viewpoint of leadership, motivation, team-work and MBA education in general. The paper suggests an alternative viewpoint to higher education and a series of concepts and ideas that can be "imported" into western business education from the Middle Kingdom.
\end{abstract}

Keywords: MBA Education; Chinese Learning; Asian Students; Eastern and Western Educational Systems

$21^{\text {st }}$ International Association of Jesuit Business Schools (IAJBS)

$18^{\text {th }}$ Colleagues in Jesuit Business Education (CJBE)

\section{Introduction}

A dominant trend among Jesuit sister schools and North American Schools of Business in general has been "going global" by transplanting pedagogy and content to educational locations in Asia and Africa. Jesuits and their schools are known worldwide for excellent rigorous educational practices. Transplanting them from one culture to another has been a hallmark, beginning with St. Ignatius Loyola's roving roommate, St. Frances Xavier, who settled into Macau where he established a base for training and dispatching teachers throughout Asia. This seminary and university continues existence and practice to the present day.

On a less grand scale, individual schools have looked to Asia as a place for both study-abroad opportunities for North and South American students as well as contexts for cooperative global ventures and exchanges. From a teaching perspective, our western schools look to these regions as contexts to provide cultural richness to our students' educational experience, to prepare Americans for dealings in the global business marketplace, and often to increase our own enrollments and revenues. The unarticulated assumption is that the Western brand of graduate business education is superior to any and all homegrown Asian versions. To date we have served as "exporters" of our own sometimes xenophobic brand of MBA education. This paper attempts to debunks myths associated with across-the-board superiority of Western graduate business education and suggests some aspects and practices that can be borrowed from China to improve the education of MBA students in the Western Hemisphere. A secondary goal is to explicate the thinking and learning styles of Asian students, so as to aid educators in better serving their needs both in the Americas and in their country of origin.

\section{Method}

This study is a qualitative exploration that focused upon the attitudes and actions of graduate business students on two continents. The author lived and taught MBA students in Shanghai, China. Using the ethnographic approach of participant observation and personal interviews, she engaged with Chinese graduate business school students both in and outside of the classroom at a distinguished Chinese business school over a two-year period between 2008 and 2010. Once back in the United States, she resumed her faculty appointment at a major Jesuit business school and continued to observe and interact with a substantial population of Chinese graduate business students who were enrolled in U.S. graduate business programs.

The template of inquiry was emergent over several years through numerous personal interactions. The qualitative observations and synopsis of conversations were recorded in journal entries by the author. As themes and observations emerged, they were discussed further with longer-term key informants and other students with whom the researcher had less-frequent or shorter contact.

The research question first surfaced at the outset of the initial teaching assignment in China. The structure and much of the content of the MBA program in Shanghai was recognizably Western, but portions of its execution seemed forced. Most notable were the palpable frustrations in attempts to encourage thoughtful and productive class discussions as well as the tension between cooperation and competition in group projects. The idea was planted that there may be an alternative model or at least a toolbox of hybrid tactics for effective graduate business education. China in particular and Asia in general present very different viewpoints of leadership, motivation, teamwork and MBA education in general. The purpose of the session is

(1) Mary Ann McGrath,Quinlan School of Business, Loyola University Chicago

E-mail: mmcgrat@luc.edu 
to examine the assumptions implicit in western MBA programs and suggest alternative viewpoints, concepts and ideas that can be "imported" into western business education from the Middle Kingdom. An ancillary goal is to offer explanations and strategies for teaching Asian students in both hemispheres.

\section{Literature}

Both the process and the results of learning in the context of higher education have been compared and contrasted in a number of studies. Tweed, Lehman and Darrin (2002) point to the divergence of the Socratic and Confucian assumptions as they are applied in the higher education process. Although the institutions appear similar in hierarchical structure and pedagogy, a more productive avenue appears in the examination of the students themselves within their cultural context. Chan (1999) purports that there are stylistic differences between Western and Chinese learners. She discusses how the Chinese mind operates and why certain styles of learning are preferred by Chinese students, similar to learning preferences that exist among U.S. students. Of greatest influence are the principles of K'ung-fu-tze, or Master Kung, a high ranking Chinese civil servant born in 551 and renamed Confucius by Jesuit missionaries (Cheng 1994). Confucianism is not a religion, but rather a set principles for managing human relationships within a hierarchically-oriented society (Oh 1991). With emphasis on family, the five constant virtues are: filial piety, faithfulness, brotherhood, loyalty, and sincerity. Corresponding cardinal relationships are: father and son, husband and wife, elder and younger brother, monarch and subject, and between friends. Confucianism emphasizes the "value of harmony, urging individuals to adapt to the collectivity, to control their emotions to avoid conflict and to maintain inner harmony" (Kirkbride and Tang, 1992). Asian business orientation leans toward the entrepreneurial with an intergenerational family focus; a first generation will concentrate on starting a business with a secure base so that those following may build on the foundations laid by their parents (Pieke 1991). Implicit in this are the Confucian principles and relationships.

Redding (1990) concludes that the Chinese display five characteristics which summarize their thinking and behavior. These include: empha- sis on perception of the concrete, non-development of abstract thought, emphasis on particulars rather than universals, practicality, and concern for reconciliation, harmony and balance. Chinese also exhibit self-effacement, a modest behavior that deems students "not worthy" before their teachers. This modesty also inhibits the honest expression of opinions so as not to embarrass or offend others. Such behavioral tendencies present a challenge both to Western teachers and researchers.

Strong emphasis is placed on maintaining face, which consists of two aspects: "lien" and "mien tsu". The former relates to the person's moral character and the latter arises from one's social status. "Lien" is granted to those who deserve it by society, but "mien tsu" may be lost by misconduct or regained or elevated through appropriate actions (Yau 1994). In the classroom students are at risk of losing face for poor performance and, conversely, the professor may lose face for failing to meet student expectations. The concept of "ch'ih" or shame is tied to that of face. Classroom behavior tends to reflect the need to maintain face and prevent shame for all individuals involved. Students tend to sit quietly in the classroom since disobedience as well as under-performance can lead to reprimands, social isolation and shame.

Chinese learning has been assumed to be rote - direct memorization in order to pass exams (Yee 1989), and substantial portions, such as the learning of Mandarin, fall into this category. A more comprehensive study by Biggs (1994) distinguished rote learning from repetitive, in which students review material numerous times, which allows them to attach additional meanings to learned material. Such an approach explains the success that Chinese students demonstrate on written examinations world-wide. Traditional China believed that an educated, civilized person should memorize the classics; being able to repeat them word-for-word shows respect and acknowledgement for great scholarly works. Such reproduction is not considered plagiarism and poses a challenge to Chinese students studying in the West as well as to faculty members monitoring their work (Martinsons and Martinsons 1996).

The respective institutions have evolved to respond to these different learning styles resulting in two very different educational systems. The following table, adopted from Yee (1989) contrasts the purpose, instructional mode and curricular orientation of the two systems:

Table 1: Contrast of Eastern Versus Western Educational Systems

\begin{tabular}{|c|c|c|}
\hline Variable & USA & East Asia \\
\hline Main Purpose & $\begin{array}{l}\text { Focus on the individual } \\
\text { Develop individual's full potential } \\
\text { Transmit cultural heritage }\end{array}$ & $\begin{array}{l}\text { Focus on local citizenry } \\
\text { Develop literate citizenry } \\
\text { Help select future leaders } \\
\text { Transmit past cultural heritage }\end{array}$ \\
\hline Instruction Mode & $\begin{array}{c}\text { Learner-centered } \\
\text { Stress understanding, application and ability } \\
\text { Use of educational psychology } \\
\text { Active Learner }\end{array}$ & $\begin{array}{c}\text { Teacher-centered } \\
\text { Stress recall of facts } \\
\text { Use of memorization } \\
\text { Examinations as motivator } \\
\text { Passive Learner }\end{array}$ \\
\hline Curricular Orientation & $\begin{array}{l}\text { Present-future orientation } \\
\text { Development of whole person } \\
\text { Social interaction promoted }\end{array}$ & $\begin{array}{l}\text { Past-present oriented } \\
\text { Strict exams to develop academic knowledge } \\
\text { Concepts first, then skills }\end{array}$ \\
\hline
\end{tabular}

Source: Adapted from Yee (1989) 
Beyond the emphasis on the communal as opposed to the individual, this table illustrates a scenario which would lead to two very divergent classroom situations. Expectations and outcome measures shape a pedagogy that makes transition from one to the other difficult and confusing for students from either system.

In contrast with this are the studies that include entrepreneurial development in Asian communities. Kirkbride and Tang (1192) point to this indigenous to China and Southeast Asia. These small businesses, most often supported by families, are prevalent, quite active, imaginative, and nimble in their responses to changes in context.

One area of undisputed difference between the East and West in the practice of business is in the arena of negotiation. Buttery and Leung (1998) stress the importance of "guanxi" or long term relationship building to have a successful negotiated agreement. Graham and Lam (2003) purport that deep understanding of what they term the underlying "cultural threads" that underpin the Chinese negotiating style will return in the development of thriving, mutually profitable business relationships. These "threads" are the interdependence and cooperation wrought from agrarianism, the morality based upon hierarchy, the holistic cognitive processing motivated by their pictorial language and general wariness and mistrust of foreigners.

Since negotiation is often part of a business curriculum, training and experience in this area is pivotal before Jesuits graduates "go forth and set the world on fire." This surfaces in the findings of this study, as the negotiations and the building of relationships happen in the student context in advance of becoming business professionals.

\section{Findings}

Two sets of findings emerged from observations on two sides of the globe. Presented first will be a thematic findings based upon participant observation within a major Graduate Business School in China. Following that is a series of suggestions for U.S. Schools of Business from Chinese graduate students who are studying in the U.S.

\section{Contributions and Learnings from Chinese Universities}

1. Nimbleness and flexibility in programming endeavors. Although steeped in and proud of 5000 years of history, Chinese Business School in the era of "Opening Up" have exhibited strong entrepreneurial energy. New schools, in addition to new programs, are created to fill perceived educational voids. Exhibited is a tenacity and agility to try new endeavors. This may seem inconsistent with the threat of losing face and experiencing accompany shame, but to ensure face-saving, any less successful ventures quickly withdrawn, vanishing from the school's historical record and the internet. In the context of energetic growth and an extremely large population valuing and seeking education, such failures are rare. This process emulates government policy, which is willing to attempt experimental changes and quickly rescind them if results are not as expected.
2. Good pay for good work. This applies to both faculty members and students. No one is expected to volunteer and all jobs are contractual and paid. This includes university service assignment and research productivity, for which bonuses are paid when publications appear in particularly prestigious journals. Students who receive scholarships are obliged to seek out a faculty member to assist as a Research Assistant, devoting an agreed-upon amount of time each week to this commitment. Expectations for teaching, research and service are clear. The down-side of this system is that it offers no tenure, only renewable contracts. Professors may choose overload assignments that include teaching in excess of 2000 hours per year. The government-regulated mandatory retirement age at 60 for men and 55 for women drives professionals to maximize their income-producing years.

3. Appreciation of Hierarchy. The Confucian principles that govern relationships in the family are articulated earlier in this paper are echoed throughout all organizations. President Shi is literally the current Father of the country and the President of a university is the father of that school. The father/leader is head of the organization and commands respect. The "children"/ underlings trust that they will be treated with fairness and respect. They trust the "father" to make good decisions on their behalf. This is in stark contrast with the egalitarian model of the U.S. organization, but not unlike the structure and reality of universities and in particular Jesuit universities. The articulation and acceptance of such hierarchy provides members of an organization, in this case faculty members, students and staff, the freedom and space to accomplish their own important work. Certainly faculty who gravitate to business schools value autonomy and independence; for them accepting such hierarchy is a challenge. If there is an understanding and acceptance that capable and respected leaders are administering programs that incorporate good communication and transparency, both Chinese and Americans can embrace the structure.

4. The Role of Pomp and Ritual. No gathering, anniversary or special occasion passes without a formal celebration. The communal nature of Chinese society motivates such assemblages, but Western on-lookers and participants find them endearing. Participants devote time to honor all passages and people involved. A crucial aspect of every celebration involves the taking of formal photographs (which is an agenda item). These are widely disseminated on the web, in newsletters, by email and text as well as on the walls of the institution. Every graduate is memorialized in a photograph that is permently exhibited within the school. Celebrations are always inclusive and communal, but also hierarchical. And no speech, dinner or gathering is complete without large, showy formal arrangements of fresh cut flowers as well as posters and banners hung throughout the institution. 
5. The Web As a Source for All Information. Chinese university websites hold information that is equivalent to an historical archive. Pages may be added or amended, but never taken down. The typical Chinese website is busier and more densely wordy than websites that we are used to perusing in the U.S., but it can also serve as a model for a publicly available repository for all types of information. For example, when the need to recount programs and activities that took place in prior years, scanning the webpage will yield calendars of events from the inception of the webpage. Early on, these pages contained translation facility into multiple languages.

6. Empowered Students. Chinese students become active, involved and committed citizens of their respective schools. Student-organized and student-run conferences, clubs, and various organizations abound. They plan and execute social events, speakers, contests and myriad activities with the support of a staff member and some funding from the school. Although fund raising is not a priority, students quickly form groups to respond to natural disasters that plagued their country. They also evidenced strong participation in and support of alumni speaker events and any networking opportunities. They appeared to place pride and participation in their school in the present before concern about procuring a job in the future. Faculty members are invited to these events, but not involved in being advisors, planning, motivation or execution. Students take pride in presenting these events to the faculty members and administration and student participation is high.

7. Collaborations and Partnerships. Evidencing their communal predisposition, Chinese Business Schools early on captured the spirit of social enterprise through partnerships with corporations, government and other universities. In effect is a system in which schools recruit corporate sponsors who pay a substantial fee to become member affiliates. These affiliates are honored with plaques in within the school and also given access to faculty members for training seminars and lectures to their employees, similar to prepaid Executive Education. Corporate representatives are treated as honored guests when they visit campus, and they in return seek to hire graduates of the school. This priority to collaborate is additionally evidenced in the many partnerships that Chinese schools have formed with business schools in the U.S. and Europe. They actively seek faculty and student exchanges. Every interaction in China is part of a web of relationships based upon favors, reciprocity and trust. In the spirit of "guanxi," once forged, a relationship and its history are never forgotten.

8. Distinctly Chinese Negotiation. Understanding this is an important lesson for both Western business people and tourists. A negotiation is not an emergent process, but rather there is a clear unarticulated goal that is agreed upon in advance. Most Asians begin a negotiation asking for ten times what they expect to obtain. Westerners tend to "split the difference," thus abandoning the process too soon. This process cannot be rushed, as time is not a consideration; rather time is considered an unlimited resource. In the forward to The Misunderstood China, Chi Lo (2004) indicates that China always has time on her side:

For 48 out of the last 50 centuries, China was the richest and most powerful country in the world. It is only since the beginning of the $18^{\text {th }}$ century that the Middle Kingdom went into an economic and political decline. (p. v)

There is palpable optimism among the vast population that these difficult days are past and that China will once again dominate the world economic stage. Understanding and participating in the dynamics of Asian negotiation will be crucial to business interactions with such a dominant economics power.

\section{Contributions from Chinese Students in the U.S.}

This second set of findings are the result of conversations with Chinese graduate business students studying in the United States. For reasons mentioned earlier in this paper and despite programs to help them adjust to their new, radically-different academic environment, these students all indicated some degree of struggle to adapt to the Western model of business education. In general, they were pleased that they had embarked on this educational venture and worked hard to learn and understand their chosen areas of study. When queried about aspects of their Chinese education that they missed in the U.S. and that might be incorporated in to their current setting within a Jesuit School of Business, three distinct areas emerged.

1. Close Relationships with Classmates and Advisors. Unlike most U.S. universities, Chinese universities structure classes of students as cohorts. For most of the students, whose families adhere to the Chinese one-child policy, the university experience is the first time they have had a chance to spend substantial amounts unstructured time with classmates of the same age and with similar backgrounds and interests. Students refer to these classmates as "sisters" and "brothers" in the absence of other siblings. Our informants indicate that they liked and missed this this arrangement, as it encourages students to build strong relationships with their classmates as well as senior schoolmates. Most Chinese college students work as "lab-mates". Senior students are advisors and serve as the leaders in a team, and junior students respect them as elders within this micro-culture. Based on these solid relationships built over time, as students advance they can later enjoy benefits from their former senior colleagues who then become part of the alumni network. These younger alumni help graduating students with career advising and work references. In addition, most Chinese colleges have advisors on staff who interact with each cohort. This advisor has access to professors in various majors so that the advisor can match the student with appropriate academic resources and customize the academic and work advice they give.

2. Required Internship and/or Exchange. Most programs require students to participate in an internship. For undergraduates this would happen during their junior year; for graduate 
students who are not employed this could happen at any time during their program. These internships are offered by college's partner companies or firms, as described in the previous section. The particular area selected will depend on the student's major and career interests. The internship is taken for course credit and students assess their learning experience in a written report that often leads to a topic for a more in-depth analysis related to a final paper in a capstone course.

3. Independent Topic for Final Thesis. Either in place of or in addition to the capstone course common in US business degree programs, Chinese universities require seniors and graduate students to choose their own topic for their thesis. The contents of this paper would be similar to the final paper or project in capstone class, but it is accomplished on an individual basis. A committee of faculty members reads and approves the final version of the thesis. This is followed by an oral defense, which is scheduled by the Graduate School Office. Only when a student has performed adequately on both the written paper and oral defense will be able to graduate. This thesis or project usually is individual work and does not require the student to attend a class. It gives flexibility to students near the end of their academic careers either to accumulate more experience in an internship or to work during their final term. Substantial academic resources are used to accomplish this program and students admit that it is a stressful process. They also view it is valuable, as it challenges their individual comprehensive skills. The telling comment that was repeated in our conversations with students is "No one can get free ride here!"

\section{Discussion and Conclusions}

The findings of this study are meant to be neither exclusive nor exhaustive. The responses of the informants are reflective of the cultures in which they reside. There is no intent to characterize one culture or approach as better than another, but only different and perhaps containing ideas that may spark improvements.

One inspiring aspect of working with Chinese students and educational institutions is their willingness to try new approaches. This entrepreneurial spirit is palpable, despite its ties to what is perceived to be a traditional and conservative culture. It would be erroneous to operate under the impression that honoring the past prevents change in the future of China. Rather, at all levels modern China operate as "works in progress"; government and academic leaders utilize their academic training as economists and engineers to experiment and adjust policies and programs based upon data from these experiments. Confucian principles emphasize harmony and care for underlings in the hierarchy. These tenets and actions are not in conflict with the ideologies articulated in the missions of Jesuit business schools and the strategic plans that guide our institutions. As Western education has reached out to and improved the Chinese educational experience, so too can the practices consistent with our values contribute to a more holistic and global perspective to students in both East and West.

\section{Acknowledgement}

The author is grateful to the Quinlan School of Business at Loyola University Chicago for support in completing this project.

\section{References}

Biggs, J. (1994). Asian learners through Western eyes: An astigmatic paradox, Australian and New Zealand Journal of Vocational Educational research, 2(2), 40-63. http://search.informit.com.au/documentSummary; $\mathrm{dn}=950303008$

Buttery, E and T. Leung (1998). The difference between Chinese and Western negotiations, European Journal of Marketing, 32(3/4), 374389. http://dx.doi.org/10.1108/03090569810204652

Chan, S. (1999). The Chinese learner - A question of style, Education and Training, 41(6/7), 2094-305. http://dx.doi. org/10.1108/00400919910285345

Cheng, Y. (1994). Education and Class: Chinese in Britain and the US. Avebury: Altersot.

Graham, J. and N. Lam (2003). The Chinese negotiation, Harvard Business Review, 81(10), 81-92. https://hbr.org/product/chinese-negotiation/an/R0310E-PDF-ENG

Kirkbride, P.A. and Tang, S.F. (1992). Management development in the Nanyang Chinese societies of Southeast Asia. Journal of Management Development, 11(2), 56-66. http://dx.doi.org/10.1108/ EUM0000000001395

Lo, Chi (2004), The Misunderstood China. New York: Pearson.

Martinsons, MG and A.B. Martinsons (1996). Conquering cultural constraints to cultivate Chinese management creativity and innovation. Journal of Management Development, 15(9), 18-35. http://dx.doi. org/10.1108/02621719610146239

Oh, T.K. (1991). Understanding managerial values and behavior among the gang of four: South Korea, Taiwan, Singapore and Hong Kong. Journal of Management Development, 10(2), 46-56. http://dx. doi.org/10.1108/02621719110141095

Pieke, F. N. (1991). Chinese educational achievement and "folk theories of success". Anthropology \& education quarterly, 22(2), 162-180. http://www.jstor.org/stable/3195919

Redding, G. (1990). The Spirit of Chinese Capitalism. New York: GP Putnam and Sons.

Tweed, R., G. Lehman and R. Darrin (2002). Learning considered within a cultural context: Confucian and Socratic approaches. American Psychologist, 57(2), 89-99. http://dx.doi.org/10.1037/0003-066X.57.2.89 
Yau, O. H. (1994). Consumer behaviour in China: Customer satisfaction and cultural values. Routledge.
Yee, A. H. (1989). Cross-cultural perspectives on higher education in East Asia: Psychological effects upon Asian students. Journal of Multilingual \& Multicultural Development, 10(3), 213-232. WOS:A1989CP32700003 